\title{
Low level jet intensification by mineral dust aerosols
}

\author{
O. Alizadeh Choobari, P. Zawar-Reza, and A. Sturman \\ Center for Atmospheric Research, University of Canterbury, Christchurch 8140, New Zealand \\ Correspondence to: O. Alizadeh Choobari (omid.alizadehchoobari@pg.canterbury.ac.nz)
}

Received: 1 December 2012 - Revised: 14 February 2013 - Accepted: 12 March 2013 - Published: 5 April 2013

\begin{abstract}
Modification of the intensity of a low level jet (LLJ) and near-surface wind speed by mineral dust is important as it has implications for dust emission and its long-range transport. Using the Weather Research and Forecasting with Chemistry (WRF/Chem) regional model, it is shown that direct radiative forcing by mineral dust reduces temperature in the lower atmosphere, but increases it in the layers aloft. The surface cooling is shown to be associated with a reduction of turbulent kinetic energy (TKE) and hence vertical mixing of horizontal momentum. Changes in the vertical profile of temperature over the regions that are under the influence of a LLJ are shown to result in an intensification of the LLJ and near-surface wind speed, but a decrease of winds aloft. These changes in the wind speed profile differ from results of previous research which suggested a decrease of wind speed in the lower atmosphere and its increase in the upper boundary layer.
\end{abstract}

Keywords. Atmospheric composition and structure (Aerosols and particles) - Meteorology and atmospheric dynamics (Mesoscale meteorology)

\section{Introduction}

The Sistan Basin is considered to be the most active source of dust in the interior of Iran (Middelton, 1986), with an average of 167 dusty days per year (Alizadeh Choobari et al., 2013a, hereafter ACJGR). The severity and number of dusty days have rapidly increased following the onset of extreme droughts in 1999 (Miri et al., 2007). Dust storms within the basin may occur at any time throughout the year, but they are more frequent from mid-May to mid-September when the strong northerly "wind of 120 days" (locally known as Levar) dominates and the region is characterized by little or no precipitation (ACJGR). As the "wind of 120 days" blows through the basin, dust particles are entrained from the basin and surrounding landscape, particularly from Hamoun Lake over northern and western parts of the basin where large amounts of erodible sediment are available, and carried through the southern dust transport corridor towards the Oman Sea by a strong northerly low level jet (LLJ) that lies over the region (ACJGR). Mineral dust therefore has a significant influence on the climate system of the basin through its direct radiative forcing (i.e. through interaction with shortwave and longwave radiation) (McCormick and Ludwig, 1967; Miller and Tegen, 1998; Weaver et al., 2002).

Low level jets (LLJs), characterized by a pronounced diurnal variation with a nocturnal peak in response to a typical nighttime surface inversion, are a typical feature of many arid and semi-arid areas, such as the Bodélé Depression in North Africa (Washington and Todd, 2005) and Sistan Basin in eastern Iran (ACJGR). Over these regions, the peak nearsurface wind speed occurs in mid-morning when vertical mixing associated with daytime buoyancy-generated turbulent kinetic energy (TKE) transfers strong winds from the jet level down to the surface (Washington et al., 2006). Therefore, LLJs play a key role in diurnal variation of near-surface wind speed (ACJGR), resulting in diurnal variation of dust emission over the regions where alluvial sediments have accumulated. They also have important implications in terms of long-range transport of wind-blown dust (Todd et al., 2008). Mineral dust aerosols, in turn, cool the surface due to backscattering and absorption of shortwave radiation, but warm the boundary layer top due to absorption of shortwave radiation during daytime (Alizadeh Choobari et al., 2012). The associated changes in the vertical profile of temperature influence the stability of the atmosphere (Miller et al., 2004), which can change the intensity of the LLJ and near-surface wind speed (Jacobson and Kaufman, 2006; Alizadeh Choobari et al., 2012). Recent studies have shown that the radiative impact of mineral dust is associated with an overall decrease of wind speed in the lower atmosphere and its increase 
within the upper boundary layer and lower free atmosphere (Alizadeh Choobari et al., 2012). However, the impact of mineral dust on vertical profiles of wind speed over the regions that are under the influence of a LLJ is currently unexplored. Here we present a numerical simulation to determine the contribution of direct radiative forcing by mineral dust to the intensity of a strong northerly LLJ and high near-surface wind speeds over arid lands of eastern Iran.

\section{Model description}

The Weather Research and Forecasting with Chemistry (WRF/Chem) regional model was applied to simulate the impact of mineral dust on vertical profiles of wind speed in eastern Iran. The dust emission scheme is based on the Goddard Global Ozone Chemistry Aerosol Radiation and Transport (GOCART) parameterization developed by Ginoux et al. (2001, 2004). The GOCART dust scheme, together with transport and deposition processes, is briefly described in Appendix A.

The rapid radiative transfer model for general circulation models (RRTMG) (Mlawer et al., 1997) for both shortwave and longwave radiation was used to include direct radiative forcing by mineral dust, while its indirect effects were not investigated as there is little or no precipitation over the region during the simulation period (ACJGR). The refractive index of mineral dust for shortwave radiation was considered to be wavelength independent and set to $1.55+0.003 \mathrm{i}$, a value consistent with previous studies over West Africa (e.g. Petzold et al., 2008; Zhao et al., 2010) because of insufficient information to constrain the refractive index of mineral dust over eastern Iran. However, the refractive index of mineral dust for longwave radiation was considered to be wavelength dependent and varies for 16 longwave spectral bands. The refractive index was calculated by volume averaging for each size bin, and Mie theory was used to estimate the extinction efficiency, the scattering efficiency and the asymmetry factor. Optical properties were then calculated by summation over all size bins.

Cloud microphysics and convection processes were represented by the Morrison (Morrison et al., 2009) and Grell 3-D (Grell, 1993) schemes, respectively. The unified Noah land-surface model (Chen and Dudhia, 2001; Ek et al., 2003), Monin-Obukhov (Janjic Eta) surface layer scheme (Obukhov, 1971) and a 2.5 level TKE-based planetary boundary layer (PBL) scheme of Mellor-YamadaNakanishi-Niino (MYNN) (Nakanishi and Niino, 2004) were used.

The nested domain of the simulation covers eastern Iran, western Afghanistan and Pakistan and a portion of Turkmenistan using $350 \times 360$ grid points at a horizontal grid spacing of $5 \mathrm{~km}$ and $27 \sigma$-levels in the vertical on a terrainfollowing coordinate system. Two simulations were performed. The first comprised a model setup that did not in- clude direct radiative forcing of aerosols, despite the inclusion of dust, and the second interactive experiment simulated the two-way interaction between atmospheric processes and aerosols. One-month simulations during July 2009 were conducted when near-surface wind speed and a northerly LLJ were strongest over the region (ACJGR). The meteorological initial and boundary conditions were generated using the National Centers for Environmental Prediction (NCEP) Final Analysis (FNL) re-analysis data at $1^{\circ}$ resolution, and the boundary conditions were updated every $6 \mathrm{~h}$.

\section{Dust effects on boundary layer dynamics}

The strong persistent northerly "wind of 120 days" is characteristic of eastern Iran and western Afghanistan from midMay to mid-September each year during which time there is considerable dust activity (McMahon, 1906; Middelton, 1986). The strongest wind is observed in July when the long-term monthly averaged wind speed at $10 \mathrm{~m}$ over Zabol $\left(31.05^{\circ} \mathrm{N}, 61.47^{\circ} \mathrm{E}\right)$, a city in eastern Iran on the border with Afghanistan, exceeds $11 \mathrm{~m} \mathrm{~s}^{-1}$ (ACJGR). The "wind of 120 days" is associated with a LLJ at around $900 \mathrm{hPa}$ with a maximum nighttime monthly averaged wind speed of more than $21 \mathrm{~m} \mathrm{~s}^{-1}$ in the LLJ core and a pronounced diurnal cycle (ACJGR). The strong "wind of 120 days" and extreme aridity of the region (e.g. annual average rainfall of $63 \mathrm{~mm}$ over Zabol) results in frequent dust storms. These occur particularly in late spring, throughout summer and early autumn, with peak activity in July (ACJGR). While the strong "wind of 120 days" contributes to a substantial amount of dust emission from the region, radiative forcing by mineral dust can also influence boundary layer dynamics, which in turn modulates the "wind of 120 days" and the LLJ that lies over the region (Fig. 1).

Atmospheric heating and cooling profiles due to the interaction of shortwave and longwave radiation with mineral dust aerosols over Zabol averaged for July 2009 are shown in Fig. 1a-c. Absorption of shortwave radiation by suspended dust is associated with atmospheric heating, with a maximum rate of $1.3 \mathrm{~K} \mathrm{day}^{-1}$ near the surface and a decreasing trend with altitude (Fig. 1a). In contrast, the interaction of suspended dust with longwave radiation results in cooling of the atmosphere as absorption of longwave radiation by dust is less than its emission to the surface and top of the atmosphere (TOA) (Alizadeh Choobari et al., 2013b). The longwave cooling effect of mineral dust has the maximum rate of around $-2.2 \mathrm{Kday}^{-1}$ near the surface, with a decreasing trend with altitude (Fig. 1b). The net radiative impact (shortwave + longwave) of mineral dust is to cool the lower atmosphere (below $200 \mathrm{~m}$ ) and warm the layers aloft (above $200 \mathrm{~m}$ ), with maximum rates of $-0.9 \mathrm{~K} \mathrm{day}^{-1}$ and $+0.3 \mathrm{~K} \mathrm{day}^{-1}$, respectively (Fig. 1c).

The absorption and backscattering of shortwave radiation by mineral dust is associated with a decrease of solar 

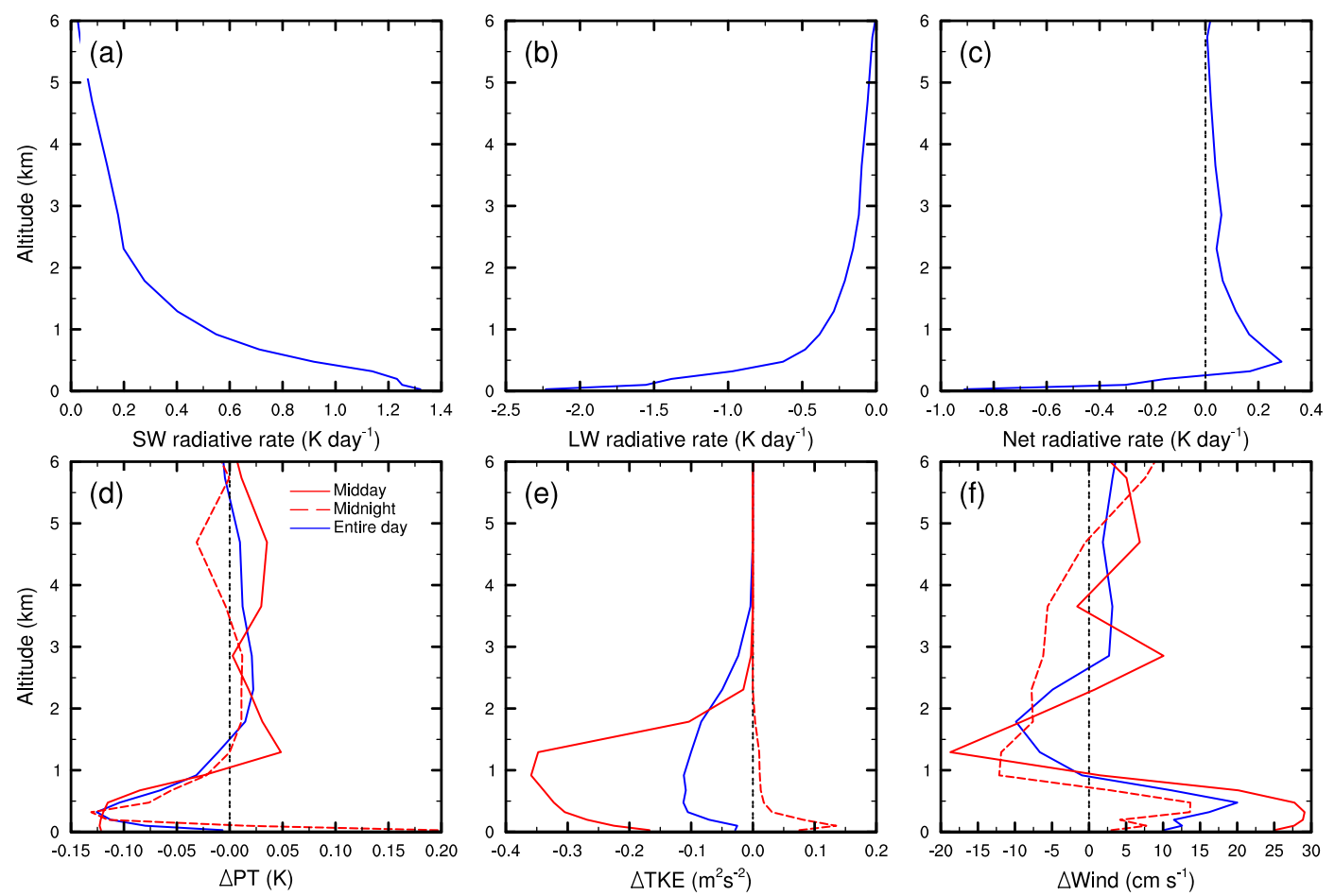

Fig. 1. Simulated atmospheric heating and cooling profiles $\left(\mathrm{Kday}^{-1}\right)$ due to the interaction of (a) shortwave, (b) longwave and (c) net radiation with dust aerosols, as well as (d) potential temperature $(\mathrm{K}),(\mathbf{e})$ turbulent kinetic energy $\left(\mathrm{m}^{2} \mathrm{~s}^{-2}\right)$ and (f) wind speed (cm s $\left.\mathrm{s}^{-1}\right)$ responses to direct radiative forcing by mineral dust averaged for July 2009 over Zabol $\left(31.05^{\circ} \mathrm{N}, 61.47^{\circ} \mathrm{E}\right)$. Daytime and nighttime profiles correspond to monthly averaged values at 12:00 (midday) and 00:00 (midnight) local times.

radiation reaching the surface, resulting in a decrease in nearsurface potential temperature during daytime. During night, on the other hand, trapping of longwave radiation results in an increase of potential temperature in the lower atmosphere (Fig. 1d). As the daytime cooling of the lower atmosphere dominates over its nighttime warming, the impact for the entire day is cooling of the lower atmosphere, with the maximum monthly averaged cooling of $-0.13 \mathrm{~K}$ at around $400 \mathrm{~m}$ above the ground surface where the core of the LLJ is located. The absorptive nature of mineral dust, on the other hand, contributes to an increase of potential temperature in the layers aloft (both day and night), with a maximum monthly averaged increase of about $0.02 \mathrm{~K}$ at around $2.5 \mathrm{~km}$. The associated changes in the vertical profile of potential temperature increase the stability of the atmosphere during the day, which results in a reduction of TKE and consequently vertical mixing of horizontal momentum (note that surface cooling and warming aloft leads to a decrease in buoyancy-generated TKE). During night, the surface warming effect of mineral dust destabilizes the atmosphere, thereby contributing to an increase of TKE and hence vertical mixing, although the radiative effect of mineral dust for the entire day is a reduction of TKE (Fig. 1e). The daytime and nighttime dust-induced changes in the vertical pro- file of potential temperature (shown in Fig. 1d) are consistent with the dust-induced changes in TKE (shown in Fig. 1e).

As wind speed is stronger in the core of the LLJ than layers above, the reduced daytime vertical mixing results in an increase of wind speed near the surface and in the core of the LLJ (Fig. 1f). Even with the increased TKE and vertical mixing at midnight, the wind speed near the surface and in the core of the LLJ is intensified by dust, although the increase is less significant than midday effects. One possible cause for the increased wind speed in the core of the LLJ during night could be related to the surface warming effect of mineral dust, which increases the north-south pressure gradient force between the thermal low-pressure system over the arid lands of eastern Iran and the persistent cold high-pressure system over the high mountains of the Hindu Kush in northern Afghanistan. The maximum increase in wind speed is simulated to be near the core of the LLJ at around $400 \mathrm{~m}$, with a monthly averaged value of $21 \mathrm{~cm} \mathrm{~s}^{-1}$. At altitudes of $0.9-2.5 \mathrm{~km}$, on the other hand, the reduced vertical mixing by dust is associated with a reduction in transfer of horizontal momentum from the jet level to layers above, leading to a decrease of wind speed, with a maximum monthly averaged reduction of $11 \mathrm{~cm} \mathrm{~s}^{-1}$ at $1.8 \mathrm{~km}$ height.

The observed and simulated air temperature at $2 \mathrm{~m}$ and wind speed at $10 \mathrm{~m}$, as well as simulated sensible heat flux 

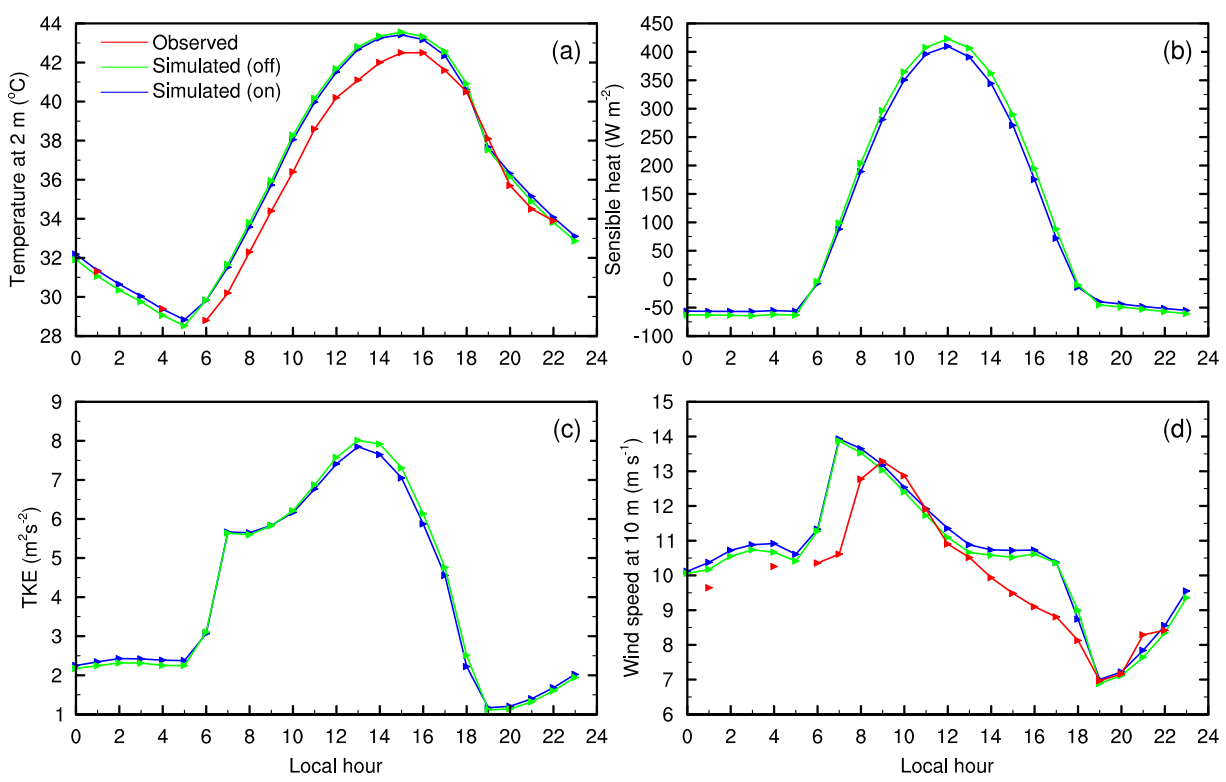

Fig. 2. The observed (red) and simulated (for radiative forcing on (blue) and off (green)) monthly averaged diurnal variation of (a) air temperature at $2 \mathrm{~m}\left({ }^{\circ} \mathrm{C}\right)$, (b) surface sensible heat flux $\left(\mathrm{W} \mathrm{m}^{-2}\right)$, (c) turbulent kinetic energy $\left(\mathrm{m}^{2} \mathrm{~s}^{-2}\right)$ in the first model layer and (d) wind

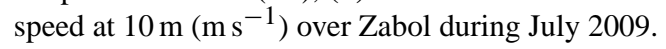

and TKE averaged for July 2009, are shown in Fig. 2. The observed data were obtained at the weather station in the city of Zabol. Near-surface air temperature and surface sensible heat flux responses to radiative forcing by mineral dust show diurnal variation due to the absence of solar radiation during night (Fig. 2a-b). Temperature at $2 \mathrm{~m}$ and surface sensible heat flux are both reduced during the day, because absorption and backscattering of solar radiation by dust aerosols dominates over the infrared trapping effect. In contrast, trapping of infrared radiation by mineral dust during night is associated with an increase in near-surface temperature and surface sensible heat flux. Simulation results indicate that daytime surface cooling and nighttime surface warming effects by dust result in a decrease and an increase of TKE, respectively (Fig. 2c), while they both contribute to an increase of wind speed at $10 \mathrm{~m}$ (Fig. 2d). These results and the rationale are similar to the discussion of Fig. 1e-f above.

Figure $2 \mathrm{~d}$ exhibits a pronounced diurnal variation of the near-surface wind speed. The peak wind speed is simulated and observed in early to mid-morning due to momentum transfer from the jet level down to the surface as the daytime mixed layer evolves, with the maximum monthly averaged observed value of $13.3 \mathrm{~m} \mathrm{~s}^{-1}$. Throughout the day, however, the mixed-layer depth continues to increase, resulting in momentum mixing over larger vertical distances, which weakens the LLJ (see Fig. 3), causing rapid reduction of wind speed at $10 \mathrm{~m}$ until the late evening when it reaches the minimum monthly averaged wind speed of about $7 \mathrm{~m} \mathrm{~s}^{-1}$. There is a lag between the simulated and observed wind speed at $10 \mathrm{~m}$, so that the peak wind speed was simulated $2 \mathrm{~h}$ prior to the measurements. One possible reason for this is simulation of higher air temperature than the observed values during the day (Fig. 2a), which leads to earlier development of the boundary layer and, consequently, earlier momentum transfer from the jet level down to the surface.

As noted by ACJGR, the northerly LLJ is geographically restricted to the border between Iran and Afghanistan, with the jet core at around $400 \mathrm{~m}$ above the ground surface exceeding the nighttime monthly averaged wind speed of $21 \mathrm{~m} \mathrm{~s}^{-1}$ (Fig. 3a). The LLJ is substantially weakened during the day (Fig. 3b) when the daytime developed well-mixed layer contributes to the vertical mixing of momentum from the jet level to layers below and above. Monthly averaged nighttime and daytime vertical cross sections of horizontal wind speed and TKE, as well as the direct radiative impact of mineral dust on them, along the line labelled $\mathrm{AB}$ in Fig. 3a, are shown in Fig. 4. The nighttime cross section is characterized by a strong LLJ (wind speed exceeding $21 \mathrm{~m} \mathrm{~s}^{-1}$ at the core of the LLJ) and low TKE values reaching up to $1 \mathrm{~m}^{2} \mathrm{~s}^{-2}$ close to the surface (Fig. 4a). In contrast, the substantial increase of TKE during the day (with a maximum daytime monthly averaged value of $9 \mathrm{~m}^{2} \mathrm{~s}^{-2}$ ) and associated vertical mixing of horizontal momentum contribute to dissipation or substantial weakening of the LLJ (Fig. 4b).

The nighttime surface warming effect of mineral dust contributes to an increase of TKE, as well as an intensification of wind speed in the lower atmosphere and the core of the LLJ, but a decrease of wind speed in layers aloft (Fig. 4c). As discussed earlier, the increased wind speed in the lower atmosphere and the LLJ intensification is related 


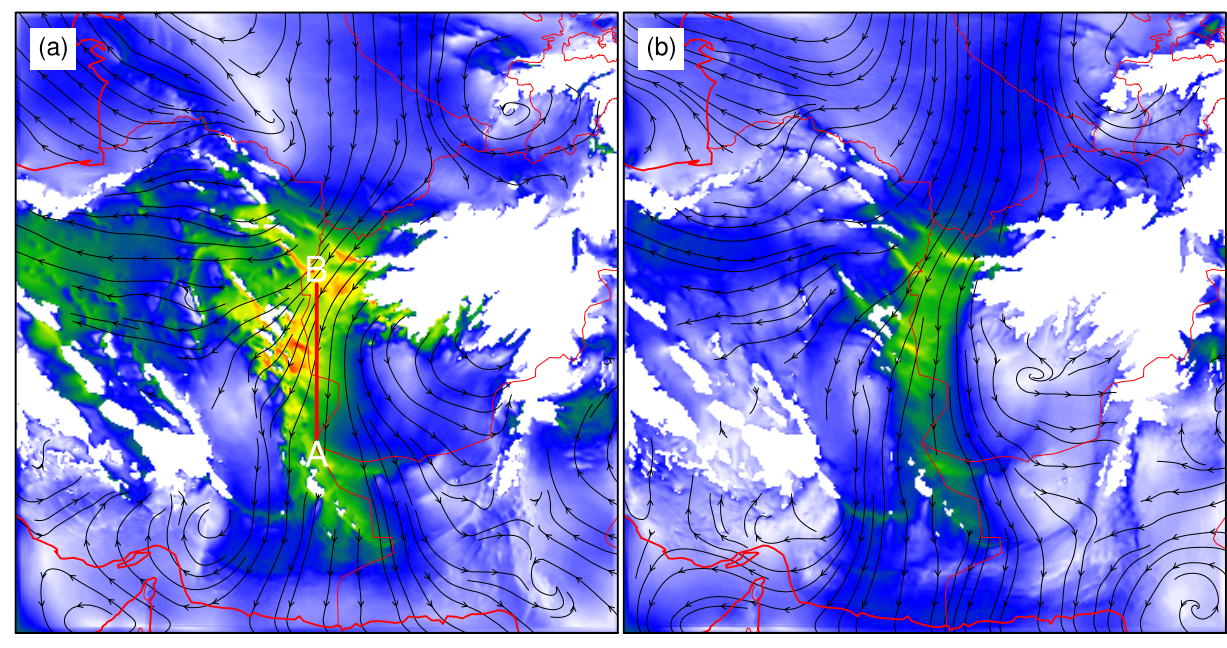

$\begin{array}{llllllllllll}0 & 2 & 4 & 6 & 8 & 10 & 12 & 14 & 16 & 18 & 20 & 22\end{array}$

Fig. 3. Simulated wind speed $\left(\mathrm{m} \mathrm{s}^{-1}\right.$ ) and streamlines at $800 \mathrm{hPa}$ at (a) 00:00 and (b) 12:00 local times averaged during July 2009. The line AB marks the vertical cross sections plotted in Fig. 4.

to the increased north-south pressure gradient force between the thermal low-pressure system over the arid lands of eastern Iran and persistent cold high-pressure system over the Hindu Kush mountains. The daytime surface cooling effect of mineral dust, on the other hand, decreases the TKE (Fig. 4d), resulting in a decrease in vertical mixing of horizontal momentum. As winds are stronger in the core of the LLJ, the reduced vertical mixing contributes to an increase of wind speed in the lower atmosphere and the core of the LLJ, but its decrease in layers above.

\section{Conclusions}

The Sistan Basin in eastern Iran and western Afghanistan has long been found to be an important source of mineral dust (McMahon, 1906; Middelton, 1986), because erodible sediment is continuously supplied from Hamoun Lake and the region is under the influence of the strong northerly "wind of 120 days" (ACJGR). The near-surface wind speed shows a pronounced diurnal variation with a peak in mid-morning. Model results indicate that the peak near-surface wind speed in mid-morning is in response to the existence of a northerly LLJ and associated transfer of momentum from the jet level down to the surface as the daytime mixed layer evolves (ACJGR). This is similar to the results of Washington and Todd (2005) and Todd et al. (2008) at the Bodélé Depression where a LLJ and associated peak near-surface wind speed were observed in mid-morning.

The "wind of 120 days" is strongest in July when the observed long-term monthly averaged wind speed at $10 \mathrm{~m}$ exceeds $11 \mathrm{~m} \mathrm{~s}^{-1}$ and the averaged nighttime wind speed at the core of the LLJ is simulated to reach as high as $21 \mathrm{~m} \mathrm{~s}^{-1}$
(ACJGR). The strong northerly "wind of 120 days" and the LLJ play a key role in dust emission and its subsequent long-range meridional transport, but direct radiative forcing by mineral dust also influences the strength of the "wind of 120 days". Simulation results of the online WRF/Chem regional model reveal that direct radiative forcing by mineral dust is associated with net daytime cooling and nighttime warming of the lower atmosphere, as well as the warming of the atmosphere above, both during the day and night. Changes in the vertical profile of temperature result in the daytime decrease and nighttime increase of TKE, both of which are associated with strengthening of the LLJ and nearsurface wind speed. The daytime increase of wind speed is attributed to the decreased TKE by mineral dust that restricts transport of momentum from the jet level to layers above, while the nighttime intensification is attributed to the strengthening of the pressure gradient force. This suggests that although previous studies have shown that mineral dust aerosols reduce wind speed in the lower atmosphere and increase it in layers above (e.g. Jacobson and Kaufman, 2006; Alizadeh Choobari et al., 2012), our results indicate an opposite effect on the vertical profile of wind speed over the regions that are influenced by a LLJ. The positive impact of mineral dust on near-surface wind speed and the LLJ has important implications for increased dust emission and its longrange transport. The results of this study suggest the importance of the application of unified online-coupled meteorology and chemistry/aerosol models (Zhang, 2008), in order to obtain more realistic meteorological characteristics.

A lack of upper-air observations limits corroboration of the existence of the LLJ that was identified by the numerical simulation and the conclusion that the peak wind speed 

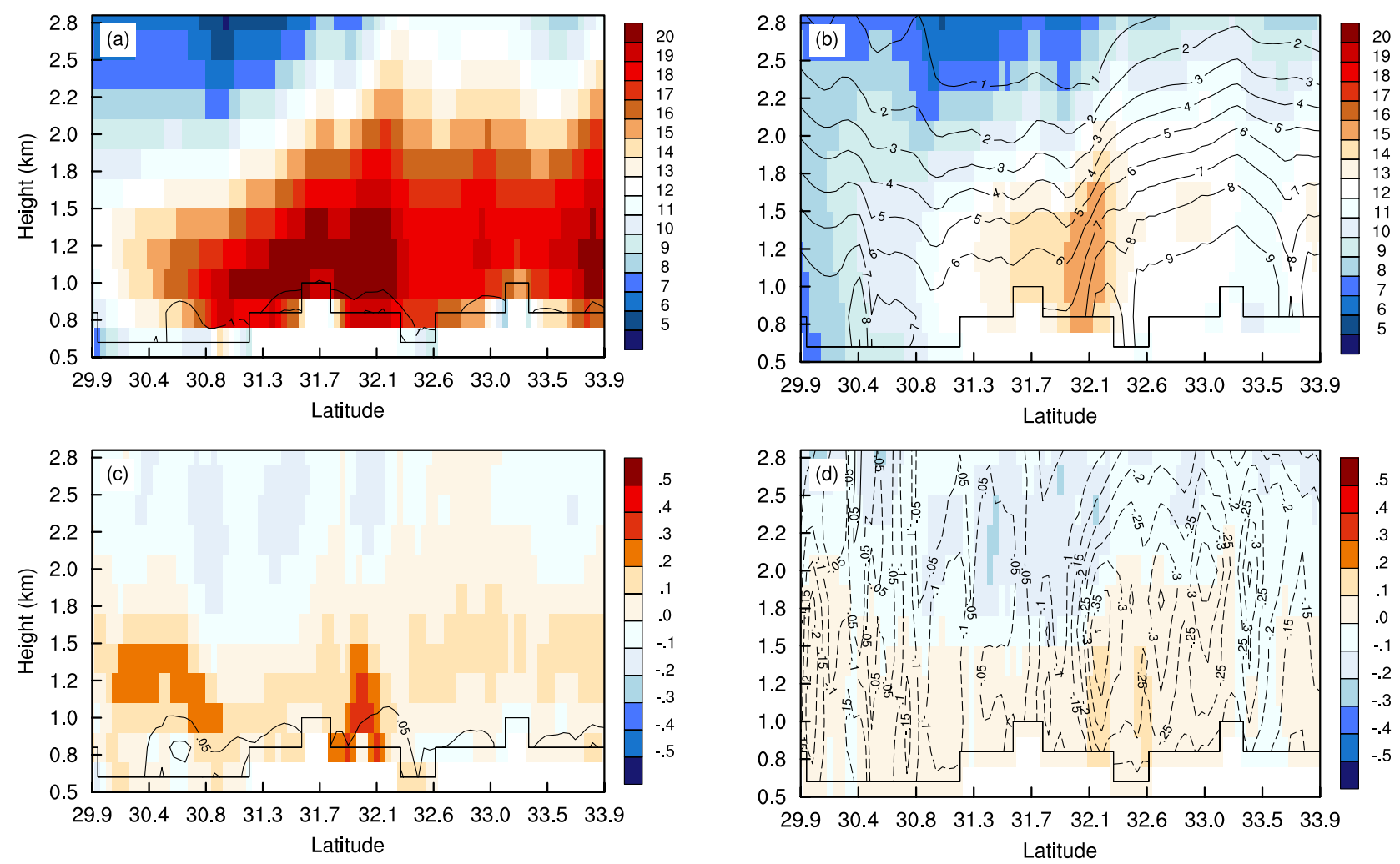

Fig. 4. Vertical cross sections (from A to B in Fig. 3a) of horizontal wind speed (colours, $\mathrm{m} \mathrm{s}^{-1}$ ) and turbulent kinetic energy (contour interval of $1 \mathrm{~m}^{2} \mathrm{~s}^{-2}$ ) from the simulation that included the direct radiative forcing (a and $\left.\mathbf{b}\right)$. The difference between simulations with radiative forcing on and off are shown in (c) and (d) (same variables as top panels, but contour interval of $0.05 \mathrm{~m}^{2} \mathrm{~s}^{-2}$ for turbulent kinetic energy). The left panels (a and $\mathbf{c})$ are for nighttime (21:00 local time) and the right panels (b and $\mathbf{d})$ are for daytime (12:00 local time).

in mid-morning is caused by the momentum transfer from the LLJ down to the surface. Upper-air observations are essential for corroborating the structure, intensity and diurnal variation of the LLJ identified in the current study, as well as for monitoring the vertical distribution of dust particles from the Sistan Basin and the height at which they are transported. As the refractive index of mineral dust depends on the mineralogy and composition of dust over a given region, field campaigns are required to identify the predominant mineralogical composition and optical properties of dust over the Sistan Basin.

\section{Appendix A}

\section{The GOCART dust scheme}

The dust simulation adopted the approach of the GOCART scheme (Ginoux et al., 2001, 2004) that considers preferential sources based on erodible fraction (Cavazos Guerra, 2011). Based on this approach, the vertical dust flux from the surface is defined as

$$
F=C S s_{\mathrm{p}} u_{10}^{2}\left(u_{10}-u_{\mathrm{tp}}\right) \quad \text { for } \quad u_{10} \geq u_{\mathrm{t}}
$$

where $C$ is a dimensional empirical constant and tuned to $1.9, u_{10}$ is the horizontal wind speed at $10 \mathrm{~m}, u_{\text {tp }}$ is the threshold velocity for wind erosion of particle size $p, s_{\mathrm{p}}$ is the fraction of each size bin of dust and $S$ is the fraction of sediments accumulated in the topographic depression regions with bare surfaces that are available for wind erosion (Chin et al., 2003). Dust particles can be blown into the atmosphere when wind speed at $10 \mathrm{~m}$ exceeds the threshold velocity, which is a function of particle size, as well as density of mineral dust and air, and is given by (Ginoux et al., 2004)

$$
u_{\mathrm{tp}}=0.13 \frac{\sqrt{\frac{\rho_{\mathrm{p}} g \phi_{\mathrm{p}}}{\rho_{\mathrm{a}}}} \sqrt{1+\frac{6 \times 10^{-7}}{\rho_{\mathrm{p}} g \phi_{\mathrm{p}}^{2.5}}}}{\sqrt{1.7638\left(4.6 \times 10^{6}\left[\phi_{\mathrm{p}}^{1.56}+1\right]^{0.092}-1\right)}},
$$

where $\rho_{\mathrm{p}}$ is the particle density $\left(\mathrm{kg} \mathrm{m}^{-3}\right), g$ is gravity $\left(9.81 \mathrm{~m} \mathrm{~s}^{-2}\right), \phi_{\mathrm{p}}$ is the effective diameter of dust particles in the size class $\mathrm{p}(\mathrm{m})$, and $\rho_{\mathrm{a}}$ is the air density. To take into account the bonding effect of soil moisture, Eq. (A2) has been 
modified (Ginoux et al., 2004):

$u_{\mathrm{twp}}= \begin{cases}u_{\mathrm{tp}} \times\left(1.2+0.2 \log _{10} w\right) & \text { if } w<0.5 \\ \infty & \text { otherwise }\end{cases}$

where $w$ is the soil moisture. Five discrete size bins of dust particles were considered, with idealized spherical shapes whose radii range from 0.1 to $10 \mu \mathrm{m}$ : $0.1-1,1-2,2-3,3-6$ and $6-10 \mu \mathrm{m}$, with corresponding effective radii of $0.73,1.4$, 2.4, 4.5 and $8.0 \mu \mathrm{m}$.

Dust particles can be transported by advection and eddy diffusion, while dry and wet deposition are removal processes. Dry deposition includes gravitational settling as a function of particle size and air viscosity, and surface deposition as a function of surface type and atmospheric stability conditions (Wesely, 1989). The wet deposition scheme considers stratiform and convective precipitation (Balkanski et al., 1993).

Acknowledgements. The authors would like to thank the Foundation for Research, Science and Technology and the National Institute for Water and Atmospheric Research (New Zealand) for their ongoing financial support. This work has also benefited from access to the BlueFern supercomputer facilities at the University of Canterbury, New Zealand.

Topical Editor P. Drobinski thanks one anonymous referee for her/his help in evaluating this paper.

\section{References}

Alizadeh Choobari, O., Zawar-Reza, P., and Sturman, A.: Feedback between windblown dust and planetary boundarylayer characteristics: Sensitivity to boundary and surface layer parameterizations, Atmos. Environ., 61, 294-304, doi:10.1016/j.atmosenv.2012.07.038, 2012.

Alizadeh Choobari, O., Zawar-Reza, P., and Sturman, A.: Mesoscale modelling of the "wind of 120 days" and associated mineral dust distribution over eastern Iran using WRF/Chem, J. Geophys. Res., submitted, 2013a.

Alizadeh Choobari, O., Zawar-Reza, P., and Sturman, A.: Simulation of the spatial distribution of mineral dust and its direct radiative forcing over Australia, Tellus B, 65, doi:10.3402/tellusb.v65i0.19856, 2013b.

Balkanski, Y. J., Jacob, D. J., Gardner, G. M., Graustein, W. C., and Turekian, K. K.: Transport and residence times of tropospheric aerosols inferred from a global three-dimensional simulation of 210Pb, J. Geophys. Res., 98, 20573-20586, 1993.

Cavazos Guerra, C. D. C.: Modelling the atmospheric controls and climate impact of mineral dust in The Sahara Desert, Ph.D. thesis, University College London, 2011.

Chen, F. and Dudhia, J.: Coupling an advanced land surfacehydrology model with the Penn State-NCAR MM5 modeling system. Part I: Model implementation and sensitivity, Mon. Weather Rev., 129, 569-585, 2001.

Chin, M., Ginoux, P., Lucchesi, R., Huebert, B., Weber, R., Anderson, T., Masonis, S., Blomquist, B., Bandy, A., and Thornton, D.:
A global aerosol model forecast for the ACE-Asia field experiment, J. Geophys. Res., 108, D23, doi:10.1029/2003JD003642, 2003.

Ek, M. B., Mitchell, K. E., Lin, Y., Rogers, E., Grunmann, P., Koren, V., Gayno, G., and Tarpley, J. D.: Implementation of Noah land surface model advances in the National Centers for Environmental Prediction operational mesoscale Eta model, J. Geophys. Res., 108, 8851, doi:10.1029/2002JD003296, 2003.

Ginoux, P., Chin, M., Tegen, I., Prospero, J. M., Holben, B., Dubovik, O., and Lin, S. J.: Sources and distributions of dust aerosols simulated with the GOCART model., J. Geophys. Res., 106, 20255-20273, doi:10.1029/2000JD000053, 2001.

Ginoux, P., Prospero, J. M., Torres, O., and Chin, M.: Long-term simulation of global dust distribution with the GOCART model: correlation with North Atlantic Oscillation., Environ. Model. Software, 19, 113-128, 2004.

Grell, G. A.: Prognostic evaluation of assumptions used by cumulus parameterizations, Mon. Weather Rev., 121, 764-787, 1993.

Jacobson, M. Z. and Kaufman, Y. J.: Wind reduction by aerosol particles, Geophys. Res. Lett., 33, L24814, doi:10.1029/2006GL027838, 2006.

McCormick, R. A. and Ludwig, J. H.: Climate modification by atmospheric aerosols, Science (New York, N.Y.), 156, 1358-1359, 1967.

McMahon, H.: Recent survey and exploration in Seistan, Geogr. J., 28, 209-228, 1906.

Middelton, N. J.: A geography of dust storms over southwest Asia, J. Climatol., 6, 183-196, 1986.

Miller, R. L. and Tegen, I.: Climate response to soil dust aerosols, J. Climate, 11, 3247-3267, 1998.

Miller, R. L., Perlwitz, J., and Tegen, I.: Feedback upon dust emission by dust radiative forcing through the planetary boundary layer, J. Geophys. Res., 109, D24209, doi:10.1029/2004JD004912, 2004.

Miri, A., Ahmadi, A., Ghanbar, A., and A., M.: Dust storms impacts on air pollution and public health under hot and dry climate, Int. J. Energy Environ., 2, 101-105, 2007.

Mlawer, E. J., Taubman, S. J., Brown, P. D., Iacono, M. J., and Clough, S. A.: Radiative transfer for inhomogeneous atmospheres: RRTM, a validated correlated-k model for the longwave, J. Geophys. Res., 102, 16663-16682, 1997.

Morrison, H., Thompson, G., and Tatarskii, V.: Impact of cloud microphysics on the development of trailing stratiform precipitation in a simulated squall line: Comparison of One- and Two-Moment Schemes, Mon. Weather Rev., 137, 991-1007, doi:10.1175/2008MWR2556.1, 2009.

Nakanishi, M. and Niino, H.: An Improved Mellor-Yamada Level3 Model with Condensation Physics: Its design and verification, Boundary-Layer Meteorol., 112, 1-31, doi:10.1007/s10546-0059030-8, 2004.

Obukhov, A. M.: Turbulence in an atmosphere with a non-uniform temperature, Boundary-Layer Meteorol., 2, 7-29, 1971.

Petzold, A., Rasp, K., WeinZierl, B., Esselborn, M., Hamburger, T., Dornbrack, A., Kandler, K., Schutz, L., Knippertz, P., Fiebig, M., and Virkkula, A.: Saharan dust absorption and refractive index from aircraft-based observations during SAMUM 2006, Tellus B, 61, 118-130, doi:10.1111/j.1600-0889.2008.00383.x, 2008.

Todd, M. C., Washington, R., Raghavan, S., Lizcano, G., and Knippertz, P.: Regional model simulations of the Bodélé low-level jet 
of northern Chad during the Bodélé Dust Experiment (BoDEx 2005), J. Climate, 21, 995-1012, doi:10.1175/2007JCLI1766.1, 2008.

Washington, R. and Todd, M. C.: Atmospheric controls on mineral dust emission from the Bodélé Depression, Chad: The role of the low level jet, Geophys. Res. Lett., 32, L17701, doi:10.1029/2005GL023597, 2005.

Washington, R., Todd, M. C., Engelstaedter, S., Mbainayel, S., and Mitchell, F.: Dust and the low-level circulation over the Bodélé Depression, Chad: Observations from BoDEx 2005, J. Geophys. Res., 111, D03201, doi:10.1029/2005JD006502, 2006.

Weaver, C. J., Ginoux, P., Hsu, N. C., Chou, M. D., and Joiner, J.: Radiative forcing of Saharan dust: GOCART model simulations compared with ERBE data, J. Atmos. Sci., 59, 736-747, 2002.
Wesely, M. L.: Parameterization of surface resistances to gaseous dry deposition in regional-scale numerical models, Atmos. Environ., 41, 52-63, 1989.

Zhang, Y.: Online-coupled meteorology and chemistry models: history, current status, and outlook, Atmos. Chem. Phys., 8, 28952932, doi:10.5194/acp-8-2895-2008, 2008.

Zhao, C., Liu, X., Leung, L. R., Johnson, B., McFarlane, S. A., Gustafson Jr., W. I., Fast, J. D., and Easter, R.: The spatial distribution of mineral dust and its shortwave radiative forcing over North Africa: modeling sensitivities to dust emissions and aerosol size treatments, Atmos. Chem. Phys., 10, 8821-8838, doi:10.5194/acp-10-8821-2010, 2010. 